\title{
Recovery of mineral oil from waste emulsion using electrocoagulation method
}

\author{
Mohd Najib Razali ${ }^{1}$, Muhamed Yusuf Shahul Hamid², Abdul Aziz Mohd Azoddein ${ }^{3}$ \\ 1,2,3 Faculty of Chemical \& Natural Resources Engineering, University Malaysia Pahang,Lebuhraya Tun Razak, 26300 Kuantan, Pahang, \\ MALAYSIA.
}

\begin{abstract}
This paper presents a research to recover mineral oil from industrial waste emulsion. This research also evaluates the standard of water produced after the oil recovery. The ecosystem could be polluted if this waste is not treated prior to discharge. The equipment needed for this experiment is power supply (generator), connecting wire and metal plate for providing the coagulant. The chosen plates were aluminium and iron plate. The power supply will be connected to the plate producing anode (positive terminal) and cathode (negative terminal). Both plates are immersed into a beaker containing waste emulsion. The charge supplied by the current will cause the aluminium or ferum to dissisipate and became ions. These ions will attract the oil to flock together and float at the surface. The water will then filter by using filter paper. Electrocoagulation was done without addition of chemical thus can prevent the hazard from the chemicals. The samples was sent for oil and grease test. The optimum time needed for recovery of oil was 3 hours. The percentage recovery reach constant trend of $95 \%$ afterwards. When the power consumption increases, the percentage recovery also increases. However, the current should be lower than 0.5 ampere as it is the limit that human body can withstand. Thus, power consumption of 27.5 Watt was chosen as optimum value. The oil recovery of at power consumption at $27.5 \mathrm{~W}$ is $96 \%$. The best plate in the process was the aluminium pair which can recover more than ferum plate. The present work concludes the promising future for waste water treatment by usage of electrocoagulation technique.
\end{abstract}

\section{Introduction}

Emulsions are a disperse systems consisting of two immiscible liquids. When oil is dispersed over continuous phase such as water, oil in water emulsion are formed [1]. The oil in water emulsions can classified into two categories, namely straight oils and soluble oils [2]. Both soluble oil and straight oil is used as cutting fluids in metal- mechanical industries to aid cutting processes, to prevent corrosion, and to improve lubrication, cooling, surface cleaning, and tool life. The cutting fluid is done by mixing small portion of cutting oil with larger portion of water.

When used in machining processes, this cutting fluid, oil in water emulsions loses its properties and effectiveness due to the thermal degradation and contamination. The replacement of these emulsions is responsible for the production of oily wastewaters. If this oil is landfilled or discharged directly without treatment, it can contaminate lakes and also river. Therefore these oils must be removed before the water is discharge or reuse [3].

The common treatment of this wastewater is membrane filtration and emulsion breaking. Membrane filtration has a problem with fouling of the membrane while emulsion breaking will need other treatment to finish the process. Electrocoagulation technique does not involve addition of chemical and is expected to produce clean water that does not need to further treat. Greenhouse gases and activated sludge is some common problems occur during treatments of wastewater using biological and chemical method. Other than that, it also required large area compared to efficiency of residual chemicals removal.

Electrocoagulation, in the other hand, removes pollutants effectively in wastewater treatment system [4]. Electrocoagulation can be used to treat many type of waste water, provided that the contaminants can react to electric field in a redox reaction. Some of electrocoagulation advantages are can manage broad type of waste, sludge reduction, and easy operating procedure with less complex control. Another benefit of electrocoagulation is hydrogen production. This gas product if been collected can act as revenue to compensate the operational cost [5].

Electrocoagulation involves three major mechanisms formulation of coagulants by electrolytic oxidation of sacrificial anodes, destabilization of the contaminants and particulate suspension, breaking of emulsions and aggregation of the destabilized phases to form a floc [6]. Electrocoagulation has been documented positively to treat the wastewater from 
steam cleaners, pressure washers, textile manufacturing, metal platers, meat and poultry processors, commercial laundry, mining operations, municipal sewage system plants and palm oil industrial effluents.

The objectives of this research is to study the effect of power (Watt), time (hours) and plate combinations to the efficiency of oil recovery from waste emulsion. In view of the fact that, no work has been done in the literature regarding the treatment of emulsion using real effluent, whereby many other studies were done using homemade synthetic effluent. Another objective is to compare treated water quality with Standard B of Industrial Effluent, Department of Environment. This is done by characterize the waste emulsion from Manufacturing and Industrial waste. The voltage was manipulated to identify the best power consumption (Watt) in order to achieve the highest oil separation efficiency in fastest time. Then, the effect of time on oil separation efficiency was studied by varying time of one to five hours with interval of one hour. Comparison of effect of using aluminium and zinc plate to find the best combination is included. Lastly, treated water quality was compared with standard A or B according to Environmental Quality Act.

\section{Materials and Method}

\subsection{Materials}

The raw material that is used for this experiment is waste emulsion from manufacturing and industrial waste. The waste is from Industrial Park, Gebeng. which had been used as lubricant and cooling oil in the process of metal drilling.

\subsection{Experimental Set-up}

Experiments were conducted in a $2 \mathrm{~L}$ beaker with the power controlled by electrocoagulation unit manufactured by Watan Technology Sdn, Bhd. The setup of equipment is done by connecting two crocodile clip wire to the power supply. The other end of the wires will be connected to plate made of aluminium and also iron. The plate connected to positive terminal of the power supply is called anode while the plate connected to negative terminal of the power supply is called cathode [7]. Both anode and cathode will be immersed in 2-litre beaker containing the waste emulsion with inter-gap of 1.5 to $3.5 \mathrm{~cm}$ between the plates to avoid short circuit. The power supply is then turned on and the voltage will be set to 20 volt while the current will be set to $1 \mathrm{amp}$ for the first trial. However, the current could not be controlled. Thus, the power value is taken according to its respective value for each voltage. The waste emulsion was leave to coagulate for three hours before filtration. The voltage was varied from 20 to 60 $\mathrm{V}$. The current vary from 0 to 6 Amps.

\subsection{Filtration Process}

Two step filtration processes were used in this experiment. The first filtration was done by using mesh filter. This kind of filter will trap the coagulated oil and help to reduce time needed for filtration process in general. Second stage filtration was done by flowing the water from first filtration through a filter paper. This step will trap remaining small particle oil which could not be filtered from first stage. After each filtration, the treated water is kept in bottle and was kept in refrigerator at temperature 4 degree Celsius to prevent bioactivities from occurring.

\subsection{Properties Analysis}

Oil and grease content was determined by using American Public Health Association 5520B method (APHA5520b). Samples were adjusted to $\mathrm{pH}$ less than two by using hydrochloric acid, $\mathrm{HCl}$ or sulphuric acid, $\mathrm{H} 2 \mathrm{SO} 4$. Water samples are sequentially extracted with three aliquots of hexane in a separator funnel. Samples are shaken vigorously for 2 minutes per extraction. The first aliquot of hexane is used to rinse the sample container so that its entire contents are transferred to the extraction vessel. The ratio of solvent to sample was set to be $50 \mathrm{~mL}$ of hexane for one extraction per $1 \mathrm{~L}$ of sample. The solvent extracts are passed through a drying funnel containing anhydrous sodium sulphate and combined together. Emulsions frequently occur during the extraction of many oil and grease samples. Precautions must be taken to ensure that adequate extraction efficiency is obtained [8]. For Oil and Grease, the extract is evaporated to dryness at ambient temperature. Following evaporation, residual water, solvent, and other volatiles are removed by heating in an oven at $50-60^{\circ} \mathrm{C}$ for $30-60$ minutes or by continued evaporation at ambient temperature, prior to gravimetric determination of the residue using at least a 4 place balance. If the final evaporation step is done at ambient temperature, gravimetric measurements must be done to constant weight [9].

\section{Results and Discussion}

The percentage of oil recovered from waste emulsion using electrocoagulation was studied by varying three parameters which were the power consumption, the time for electrocoagulation and also the type of plate used. Initially the voltage and the current were to be tested separately. However, as we increase the voltage, the current also increase. Thus power which is the product of current and voltage were used as manipulative variable. The plates available are aluminium and iron which were compared.

\subsection{Effect of Power Consumption}

Power consumption was chosen as important factor in electrocoagulation process. The power consumption is the product of voltage and current, $\mathrm{V}=\mathrm{IR}$. The voltage is 
set to the electrocoagulation unit and the responding current was noted. The voltage ranged from $20 \mathrm{~V}$ to $60 \mathrm{~V}$ and the power was shown in table below. Other parameters were kept constant during the experiment. The time for electrocoagulation was 3 hours and the plate was aluminium pair with inter-gap of $5 \mathrm{~cm}$. No adjustment was done to the $\mathrm{pH}$ value and the experiment was done at room temperature.

Table 1: Effect of power towards oil recovery percentage

\begin{tabular}{|l|l|l|l|}
\hline $\begin{array}{l}\text { Power } \\
\text { (Watt) }\end{array}$ & $\begin{array}{l}\text { Oil Content } \\
\text { before } \\
\text { treatment } \\
\text { (mg/L) }\end{array}$ & $\begin{array}{l}\text { Oil Content } \\
\text { after } \\
\text { Treatment } \\
(\mathbf{m g} / \mathbf{L})\end{array}$ & $\begin{array}{l}\% \\
\text { Recovered }\end{array}$ \\
\hline 0 & 642 & 642 & 0 \\
\hline 5 & 642 & 32.3 & 94.97 \\
\hline 6.9 & 642 & 37.6 & 94.14 \\
\hline 18 & 642 & 29.1 & 95.47 \\
\hline 27.5 & 642 & 26.1 & 95.93 \\
\hline 34.2 & 642 & 10.8 & 98.31 \\
\hline
\end{tabular}

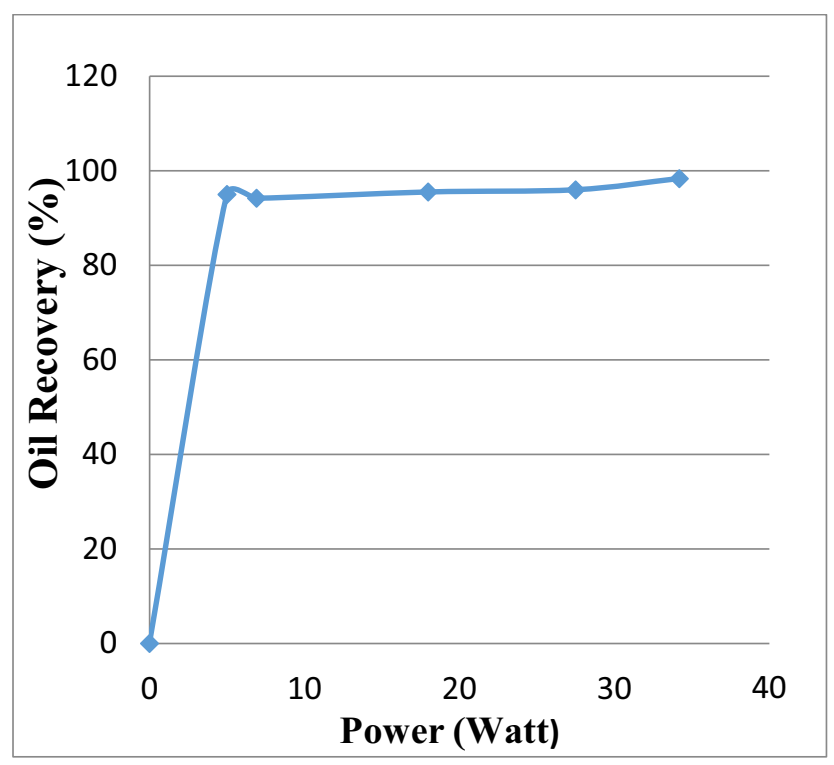

Figure 1: Oil recovery rate for several power adjustments

Table 1 and Figure 1 show the effect of power to oil recovery of oil from waste emulsion. At power of 5 watt, the recovery of oil is already very high which is 95 percent while at the highest power consumption of 34.2 Watt; the percentage recovery of oil is more than 98 percent. The efficiency of oil recovery is mainly affected by the current density. Current density is defined as current applied per unit surface area of the electrode. Generally, more applied current density results in more removal of solutes, after some value of current density, the dissipation of metal became saturated by the increase of current density [10]. The current control the amount of dissociated of aluminium into the waste water [11].
The current density not only determines the metal coagulant dissolution rate but also determines the bubble production rate and the size of the bubble generated in the electrode reaction, which influences the treatment efficiency of the electrocoagulation. As the current increase, the amount of aluminium dissipate into the waste emulsion also increases. Thus the amount of smaller flocculation will increase and the oil can coagulate better. However, higher current might cause fatality when accident happens. The safe levels of current as stated by [12] are 0.5 for direct current and 0.1 for alternating current.

\subsection{Effect of Electrocoagulation Time}

Coagulant concentration produced by electrolysis on anodes is directly proportional to the electric charge added per volume. Coagulant produced by electrolysis can be calculated according to Faraday's law when current and treatment times are known. Electrolysis time also affects the treatment efficiency of the electrochemical process as it may increase or decrease with current density or $\mathrm{pH}$ of the sample [13]. Time for coagulation to take place was varied from one hour to five hours with interval of one hour with power maintained at 27.5 Watt. The plate for each run was aluminium pair with inter-gap of $5 \mathrm{~cm}$. No adjustment was done to the $\mathrm{pH}$ value and the experiment was done at room temperature. The results were display in table 2 .

Table 2: Oil recovery rate for several time parameters

\begin{tabular}{|l|l|l|l|}
\hline $\begin{array}{l}\text { Time } \\
\text { (Hour) }\end{array}$ & $\begin{array}{l}\text { Oil Content } \\
\text { before } \\
\text { treatment } \\
(\mathbf{m g} / \mathbf{L})\end{array}$ & $\begin{array}{l}\text { Oil Content } \\
\text { after } \\
\text { Treatment } \\
(\mathbf{m g} / \mathbf{L})\end{array}$ & $\begin{array}{l}\% \\
\text { Recovered }\end{array}$ \\
\hline 0 & 642 & 642 & 0 \\
\hline 1 & 642 & 642 & 0 \\
\hline 2 & 642 & 35 & 94.55 \\
\hline 3 & 642 & 29.1 & 95.47 \\
\hline 4 & 642 & 29 & 95.48 \\
\hline 5 & 642 & 26 & 95.95 \\
\hline
\end{tabular}




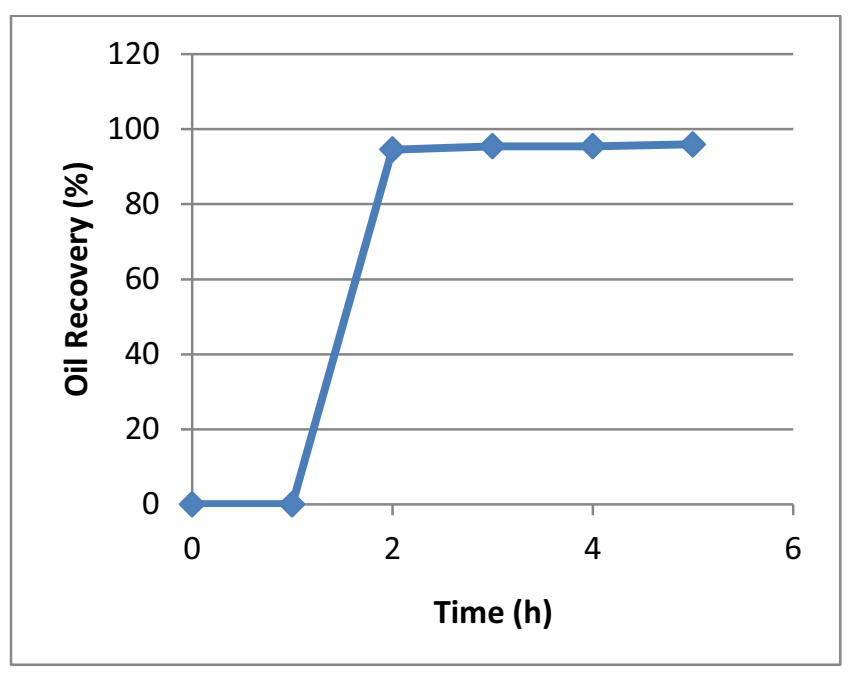

Figure 2: Effect of time towards oil recovery rate

Figure 2 demonstrate the effect of time on recovery of oil. From duration 1 to 2 hour, the oil recovery increase rapidly from $0 \%$ to $94.54 \%$ and start to constant at 3 hours and above. Time of electrocoagulation is one of the most important parameter in the process of electrocoagulation. It is the time to generate metal hydroxides and to complete coagulation of the impurities [14]. For 1 hour electrocoagulation time, the treated water was not able to filter. This may be due to the particle did not have enough time to form floc and coagulate together. Thus the oil and grease content is assumed to be the same as initial oil and grease content which is $642 \mathrm{mg} / \mathrm{L}$. At time more than 3 hours, the recovery percentages remain constant at $95 \%$ which shows the limit of the electrocoagulation method. The reaction might have ended as per the observation; the water is separated from the oil and became clear. The water also became hot at longer time.

\subsection{Effect of Metal Plate}

Plate selection was the last parameter studied in this paper. Electrode material plays vital roles for the maximizing the efficiency of the EC process. Aluminium and ferum were selected since it was proven applicable to treat oily wastewater [15] at room temperature and the inter-gap was maintained at $5 \mathrm{~cm}$. No adjustments were done to initial $\mathrm{pH}$. The power was maintained at 27.5 Watt with electrocoagulation time of 3 hours.

Table 3: Plate combination effect on oil recovery

\begin{tabular}{|l|l|l|l|}
\hline $\begin{array}{c}\text { Plate } \\
\text { Combination }\end{array}$ & $\begin{array}{c}\text { Oil Content } \\
\text { before } \\
\text { treatment } \\
(\mathbf{m g} / \mathbf{L})\end{array}$ & $\begin{array}{c}\text { Oil Content } \\
\text { after } \\
\text { Treatment } \\
(\mathbf{m g} / \mathbf{L})\end{array}$ & $\begin{array}{c}\% \\
\text { Recovered }\end{array}$ \\
\hline $\mathrm{Al} / \mathrm{Al}$ & 642 & 26.1 & 95.93 \\
\hline $\mathrm{Al} / \mathrm{Fe}$ & 642 & 30 & 95.32 \\
\hline $\mathrm{Fe} / \mathrm{Fe}$ & 642 & 56 & 91.28 \\
\hline
\end{tabular}

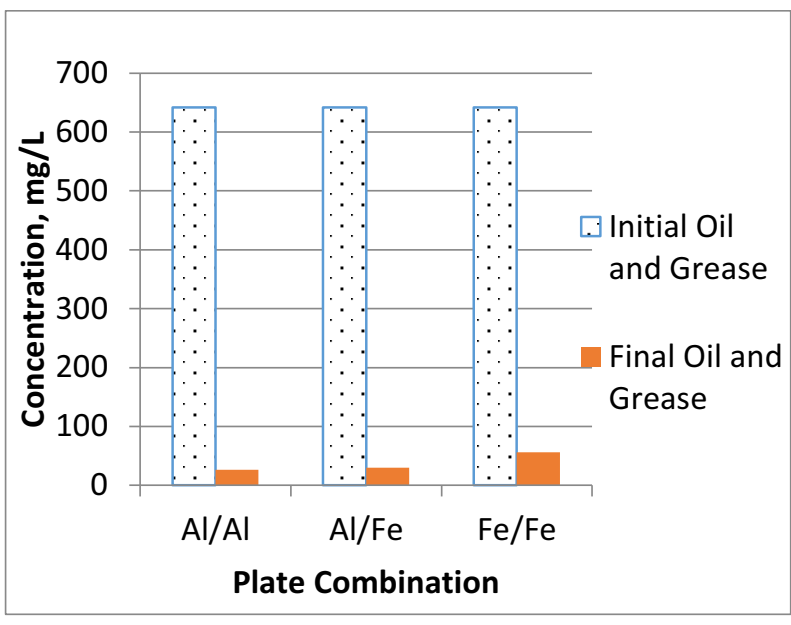

Figure 3: Oil and Grease content before and after treatment for several plate combinations

Figure 3 portrays oil content in the waste emulsion before treatment and after treatment. From the graph, it shows all combination of plate can be used to recover the oil. The oil recovery using aluminium pair was the highest with $96 \%$ and the lowest oil recovery was by using iron pair with $90 \%$ oil recovery percentage. [15] stated that aluminium and iron is the most suitable electrode for wastewater that contains metal. According to electronegativity series, the position of iron is lower than aluminium [16]. As the list goes down, the electronegativity increases. This means the tendency for the element to ionize decrease. Thus iron is harder to dissociate to become iron ion as compared to aluminium. As aluminium can dissipate easily it, the concentration of aluminium is the water increase and can coagulate more than iron.

There are many chemical reactions that take place during the electrocoagulation process. Metal anodes are reduced during electrocoagulation process will produce hydroxide complexes. The hydroxide complex is what will move the mechanism of flocculation of suspended solids into stable form. Dissociation of water by EC generate hydroxide ions which are known as one of the most reactive aqueous radical specie and this radical has the ability to oxidize organic compounds because of its high affinity value of $136 \mathrm{kcal}$ [17]. Production of oxygen and hydrogen as a result of electrolytic dissociation of water molecules cause emulsified oil droplets to be freed from water molecules making a separate layer on the surface.

In principle, it is based on the production of metallic hydroxide flocs as coagulants within the sample during electrochemical reaction through dissolution of the anode material. Electrocoagulation differs from chemical coagulation (CC) mainly in the mode of introduction of coagulants. Whereas point addition of coagulants is done in chemical coagulation, coagulants are generated across a wide range of electrode surface in electrocoagulation. Following reactions are carried out at different electrodes:

Anode: 
$\mathrm{Al}-3 \mathrm{e} \rightarrow \mathrm{Al}^{3+}$

Alkaline condition:

$\mathrm{Al}^{3+}+\mathrm{OH}^{-} \rightarrow \mathrm{Al}(\mathrm{OH})_{3}$

Electrocoagulation for Treatment of Industrial Effluents and Hydrogen Production

Acidic condition:

$\mathrm{Al}^{3+}+3 \mathrm{H}_{2} \mathrm{O} \rightarrow \mathrm{Al}(\mathrm{OH})_{3}+3 \mathrm{H}^{+}$

$2 \mathrm{H}_{2} \mathrm{O}-4 \mathrm{e} \rightarrow \mathrm{O}_{2}+4 \mathrm{H}^{+}$

Cathode:

$2 \mathrm{H}_{2} \mathrm{O}+2 \mathrm{e} \rightarrow \mathrm{H}_{2}+2 \mathrm{OH}^{-}$

$\mathrm{Al} 3+$ and $\mathrm{OH}-$ ions generated by electrode reactions (1) and (2) react to form various monomeric species such as $\mathrm{Al}(\mathrm{OH}) 2+, \mathrm{Al}(\mathrm{OH}) 2+, \mathrm{Al}(\mathrm{OH}) 24+$, and $\mathrm{Al}(\mathrm{OH}) 4-$ polymeric species such as $\mathrm{Al} 6(\mathrm{OH}) 153+$, Al7 $(\mathrm{OH}) 174+, \mathrm{Al} 8(\mathrm{OH}) 204+, \mathrm{Al} 3 \mathrm{O} 4(\mathrm{OH}) 247+$ and $\mathrm{Al13}(\mathrm{OH}) 345+$, which transform finally into $\mathrm{Al}(\mathrm{OH}) 3$ according to complex precipitation kinetics. Several interaction mechanisms are possible between organic molecules and hydrolysis products, and the rates of these depend on the $\mathrm{pH}$ of the medium and types of ions present. Freshly formed amorphous $\mathrm{Al}(\mathrm{OH}) 3$ sweep flocs have large surface areas, which is beneficial for a rapid adsorption of soluble organic compounds and trapping of colloidal particles. These flocs polymerize as $\mathrm{A} \ln (\mathrm{OH}) 3 \mathrm{n}$ and they are removed easily from the aqueous medium by sedimentation and by $\mathrm{H} 2$ flotation [18].

The following main reactions occur in the EC when Fe electrode is used:

Anode reactions:
$\mathrm{Fe}(\mathrm{s}) \rightarrow \mathrm{Fe}(\mathrm{aq})^{2+}+2 \mathrm{e}^{-}$
$\mathrm{Fe}(\mathrm{s}) \rightarrow \mathrm{Fe}(\mathrm{aq})^{3+}+3 \mathrm{e}^{-}$

Cathode reactions:

$3 \mathrm{H} 2 \mathrm{O}+3 \mathrm{e}^{-} \rightarrow(3 / 2) \mathrm{H} 2 \uparrow+3 \mathrm{OH}^{-}$

Similarly, ferric ions generated by electrochemical oxidation of iron electrode may form monomeric species $\mathrm{Fe}(\mathrm{OH}) 2+, \quad \mathrm{Fe}(\mathrm{OH}) 2+, \quad \mathrm{Fe}(\mathrm{OH}) 63+$, $\mathrm{Fe}(\mathrm{H} 2 \mathrm{O}) 5 \mathrm{OH} 2+, \mathrm{Fe}(\mathrm{H} 2 \mathrm{O}) 4 \mathrm{OH} 2+, \mathrm{Fe}(\mathrm{OH}) 3$, and $\mathrm{Fe}(\mathrm{OH}) 4-$, and polymeric species (Fe2(H2O)8OH24+, $\mathrm{Fe} 2(\mathrm{H} 2 \mathrm{O}) 6 \mathrm{OH} 42+$, depending on the $\mathrm{pH}$ of the aqueous medium in the EC process. When Fe electrodes is used the amount and the variety of hydrolysis products formed by anodic dissolution depends significantly on electrolysis time. The resulting metal hydroxide polymers have amorphous structures with very large surface and positive charges. They are hydrophobic, causing them to sorb onto the organic anionic particle surfaces and become insoluble. Iron has a strong tendency to form insoluble complexes with a number of ligands, especially with polar molecules and with oxygen-containing functional groups such as the hydroxyl or carboxyl groups. These provide a local negative charge, which reacts with the iron cations. Charge neutralization leads to colloid destabilization with the consequent precipitation of the iron cations and organic anions. This induces sweep floc coagulation, the adsorption and bridging enmeshment of both particulate organic and inorganic solids to form large, amorphous flocs. Dissolved organic compounds are removed primarily by adsorption onto by hydroxide surface [18].

\subsection{Characterization of Waste emulsion and Treated Waste Water}

The water produces from this treatment need to be examined further before we can conclude that the electrocoagulation method was suitable for oil recovery process from waste emulsion. Thus the optimum conditions from previous experiment were selected for this analysis purpose. The electrode chosen was aluminium pair with inter-gap of $5 \mathrm{~cm}$. The time for coagulation was set to 3 hours and the power used was 27.5 Watt. No adjustment was done to the $\mathrm{pH}$ value and the experiment was done at room temperature.

Table 4: Comparison of treated waste water and raw waste emulsion

\begin{tabular}{|c|c|c|c|c|}
\hline Parameter & Unit & $\begin{array}{c}\text { Standard } \\
\text { B }\end{array}$ & $\begin{array}{c}\text { Waste } \\
\text { Emulsion }\end{array}$ & $\begin{array}{c}\text { Treated } \\
\text { Waste } \\
\text { Water } \\
\end{array}$ \\
\hline $\begin{array}{l}\text { Percentage of } \\
\text { Oil }\end{array}$ & $\%$ & - & 0.13 & 0.004 \\
\hline $\begin{array}{l}\text { Percentage of } \\
\text { Water }\end{array}$ & $\%$ & - & 99.87 & 99.97 \\
\hline Temperature & ${ }^{\circ} \mathrm{C}$ & 40 & - & \\
\hline $\mathrm{pH}$ Value & - & $5.5-9.0$ & 3.48 & 6.99 \\
\hline BODS at $20^{\circ} \mathrm{C}$ & $\mathrm{mg} / \mathrm{L}$ & 50 & 58 & 72.5 \\
\hline COD & $\mathrm{mg} / \mathrm{L}$ & 100 & $\begin{array}{c}\text { More than } \\
1500\end{array}$ & 130 \\
\hline $\begin{array}{l}\text { Suspended } \\
\text { Solid }\end{array}$ & $\mathrm{mg} / \mathrm{L}$ & 100 & 1341 & 27 \\
\hline Arsenic & $\mathrm{mg} / \mathrm{L}$ & 0.10 & $\begin{array}{c}\text { Not } \\
\text { Detected }\end{array}$ & $\begin{array}{c}\text { Not } \\
\text { Detecte } \\
\text { d }\end{array}$ \\
\hline Cyanide & $\mathrm{mg} / \mathrm{L}$ & 0.10 & $\begin{array}{c}\text { Not } \\
\text { Detected }\end{array}$ & $\begin{array}{l}\text { Less } \\
\text { than } \\
0.01\end{array}$ \\
\hline Phenol & $\mathrm{mg} / \mathrm{L}$ & 1.0 & $\begin{array}{c}\text { Not } \\
\text { Detected }\end{array}$ & 1.44 \\
\hline Free Chlorine & $\mathrm{mg} / \mathrm{L}$ & 2.0 & $\begin{array}{c}\text { Not } \\
\text { Detected }\end{array}$ & 0.28 \\
\hline Sulphide & $\mathrm{mg} / \mathrm{L}$ & 0.5 & 0.245 & \\
\hline $\begin{array}{l}\text { Oil and } \\
\text { Grease }\end{array}$ & $\mathrm{mg} / \mathrm{L}$ & 10.0 & 642 & 21.3 \\
\hline
\end{tabular}

Table 4 shows the comparison between raw waste emulsion and treated waste emulsion using electrocoagulation method. The initial percentage of oil in the solution was $0.13 \%$ and the remaining was water. From the table, the percentage of oil decrease from $0.13 \%$ to $0.004 \%$. This indicates the electrocoagulation method was successful in removing oil from the waste emulsion. The oil and grease content were reduced greatly from 642 to $21.3 \mathrm{mg} / \mathrm{L}$. The percentage of oil removed was $96.6 \%$ 
The water became clearer after electrocoagulation process and the $\mathrm{pH}$ value of the treated waste emulsion was around the neutral value, $\mathrm{pH} 7$. The Chemical Oxygen Demand (COD) value was almost complies with Standard B of Environmental Quality Act (EQA). COD was removed from more than 1500 to $130 \mathrm{mg} / \mathrm{L}$. The total suspended solid (TSS) also decrease to accepted level of below $100 \mathrm{mg} / \mathrm{L}$. The final value of TSS was $27 \mathrm{mg} / \mathrm{L}$

However, some parameter shows increase values from the EQA standard. Phenol, Chlorine and Cyanide were not detected in the raw waste emulsion but were detected after the treatment. Cyanide and chlorine were within the standard B while phenol values increase above the limit. The treated waste water contains 1.44 $\mathrm{mg} / \mathrm{L}$ phenol which was $0.44 \mathrm{mg} / \mathrm{L}$ above the standard.

The biological oxygen demand (BOD) also shows increased value from 58 to $72.5 \mathrm{mg} / \mathrm{L}$. This might be due to storage problem before the sample was sent for analysis. The arsenic content remains undetected for both waste emulsion and treated waste emulsion.

\section{Conclusions}

The present exploratory works showed that electrocoagulation can be made into treatment method for oily wastewater with foreign substance such as metal particle. The optimum condition could be chosen from the highest percent of oil recovery. The most suitable plate combination would be aluminium with aluminium pair as it has more tendencies to dissociate into the wastewater as compared to iron plate. The optimum time needed for coagulation of $1.25 \mathrm{~L}$ of waste sample is 3 hours as percentage recovery reach constant trend of $95 \%$ afterwards. According to figure 1, oil was recovered the most at the highest power. However, the optimum value should be chosen at current less than 0.5 Amp in order to be more environmental friendly. Current more than 0.5 Amp could be fatal to human being. Thus Power value of 27.5 Watt should be chosen as the current is less than 0.5 Amp but still with a high oil recovery of $96 \%$. The cost for electrocoagulation is will also be lower at rate of 2.3 cent/L. However, when compared with Standard B of Environmental Quality Act, the treated water oil and grease content is higher than $10 \mathrm{mg} / \mathrm{L}$. This indicates that the treated water needs further treatment to comply with the standard B.

\section{References}

1. Binks, B.P. (ed.) (1998) Modern Aspectsof Emulsion Science. The Royal Society of Chemistry Publication.

2. Foltz, G., (2002). Fluid fundamentals. In: Lewis, M. (Ed.), Cutting Technology.

3. W. I. Jang, Y. C. Lee (2000) Removing oil from oil-in-water emulsion using Electrical
Demulsification Method. Journal of Industrial and Engineering Chemistry. Pg.85-92

4. Nasution, M.A., et al., (2011) Electrocoagulation of Palm Oil Mill Effluent as Wastewater Treatment and Hydrogen Production Using Electrode Aluminum Journal of Environmental Quality. doi:10.2134/jeq2011.0002.

5. E.H. Ezechi, M.H. Isa, S.R.M. Kutty (2010). Removal of boron from produced water by electrocoagulation. 10th WSEAS International Conference on Environment, Ecosystems and Development (EED'12), Switzerland

6. A. Golder, A. Chanda, A. Samanta, S. Ray, (2007) Removal of $\mathrm{Cr}(\mathrm{VI})$ from aqueous solution: Electrocoagulation vs chemical coagulation, Sep. Sci. Technol. 42 pg. $2177-$ 2193

7. Al-Shannag, M., Al-Qodah, Z., Bani-Melhem, K., Qtaishat, M. R., \& Alkasrawi, M. (2015). Heavy metal ions removal from metal plating wastewater using electrocoagulation: Kinetic study and process performance. Chemical Engineering Journal, 749-756.

8. Columbia, E. -P. (2011). OIL AND GREASE in WATER by HEXANE EXTRACTION AND GRAVIMETRY - PBM. Organics.

9. Hach. (2012). Oil and Grease. USA.

10. Sayiner G, F. Kandemirli, A. Dimoglo Evaluation of boron removal by electrocoagulation using iron and aluminum electrodes Desalination, 230 (2008), pp. 205212

11. M.Y.A. Mollah, R. Schennach, J.R. Parga, D.L. Cocke (2001) Electrocoagulation (EC) science and applicationsJ. Hazard. Mater., pp. $29-41$

12. Merck (1997) "Electrical Injuries." The Merck Manual of Medical Information: Home Edition. Pennsylvania

13. Abdel-Gawad, AM, B., KA, O., \& MM, M. (2012). Removal of some pesticides from the simulated waste water by electrocoagulation method using iron electrodes. Int $J$ Electrochem Sci, 66546665 .

14. Z.V.P. Murthy, Snehal Parmar (2011) Removal of strontium by electrocoagulation using stainless steel and aluminum electrodes. Desalination. Pg 63-67 
15. Y.M. Slokar, A.M. Le Marechal (1998) Methods of decoloration of textile wastewaters Dyes Pigm., 37 pp. 335-356 Alan G. Macdiarmid,

16. Alan J. Heeger, Paul J. Nigrey (1985) Secondary batteries based on reversible electrochemical doping of conjugated polymers. United States Patent.
17. Li, Y. e. (2003). Aniline degradation by electrocatalytic oxidation. Chemosphere, 53, 1229-1234.

18. Kobyaa, M., Ciftcia, C., Bayramoglub, M., \& Sensoya, M. (2008). Study on the treatment of waste metal cutting fluids using electrocoagulation. Separation and Purification Technology, 60(3), 285-291. doi:doi:10.1016/j.seppur.2007.09.003 